\title{
COUMARINS OF THE ROOTS OF Cryptodiscus didymus
}

N. S. Ignat'eva, V. V. Vandyshev,

UDC $577.15 / 17: 582.89$ and M. G. Pimenov

Cryptodiscus didymus (Regel) is a perennial monocarpic plant of the family Umbelliferae, growing in the clayey wastelands of central Asia and southern Kazakhstan [1], which has been investigated earlier for the presence of coumarins [2,3]. Ten coumarins haye been detected by chromotography in the fruit, and among these prangenin, isoimperatorin, oxypeucedanin, bergapten, imperatorin, and osthole have been identified. Later, umbelliprenin, bergapten, xanthotoxol, prangenin hydrate, and isoimperatorin were preparatively isolated from the fruit [4].

The roots of $C$. didymus have not been studied previously. We have investigated the coumarin composition of the roots of the plant collected in the Alma-Ata oblast in June, 1971. The raw material was treated with methanol, and the extract was evaporated to small volume. A substance was obtaind which identified on the the basis of its physicochemical properties and IR spectra as sucrose. Then the extract was diluted with water, the coumarin substances were extracted with diethyl ether, and the extract was dried over anhydrous sodium sulfate and concentrated until the solvent had been eliminated. The residue contained no less than five coumarins, with $\mathbf{R}_{f} 0.65,0.55,0.40,0.11$, and 0.0 [petroleum ether (bp $40-70^{\circ} \mathrm{C}$ ) on $\mathrm{F} \mathrm{N}-2$ paper impregnated with formamide-acetone $(1: 3)]$.

By column chromatography on acidic alumina [5] with elution by benzene and benzene- ethyl acetate, four individual coumarins were isolated from the extract. On the basis of their physicochemical constants, IR spectra, and melting points with authentic samples, they were identified as isoimperatorin ( $R_{f} 0.65$; yield $0.65 \%)$, pranchimgin $\left(\mathrm{R}_{f} 0.55\right.$; yield $\left.0.40 \%\right)$, imperatorin $\left(\mathrm{R}_{f} 0.40 ; 0.20 \%\right)$, and oxypeucedanin $\left(\mathrm{R}_{f} 0.11\right.$; yield $0.50 \%$ ). This is the first time that an acyloxydihydrofurocoumarin - pranchimgin - has been isolated from plants of the genus Cryptodiscus.

\section{LITER AT URE CIT ED}

1. Flora of the USSR [in Russian], Vol. 16, Moscow-Leningrad (1950).

2. N. F. Komissarenko, Khim. Prirodn. Soedin., 177 (1969).

3. I. G. Zoz and N. F. Komissarenko, Farmats. Zh., 24, No. 1, 44 (1969).

4. G. K. Niknov and I. A. Saidkhodzhaev, Khim. Prirodn. Soed in., 115 (1971).

5. V. G. Chernobai and D. G. Kolesnikov, Dokl. Akad. Nauk, SSSR, 133, 233 (1960).

I. M. Sechenov Medical Institute. All-Union Sci entific-Research Instiute of Medicinal Plants. Translated from Khimiya Prirodnykh Soedinenii, No. 4, pp. 515-516, July-August, 1974. Original article submitted F ebruary 18, 1974.

(c1976 Plenum Publishing Corporation, 227 West 17th Street, New York, N.Y. 10011. No part of this publication may be reproduced, stored in a retrieval system, or transmitted, in any form or by any means, electronic, mechanical, photocopying, microfilming, recording or otherwise, without written permission of the publisher. A copy of this article is available from the publisher for $\$ 15.00$. 